DOI: $10.20287 /$ doc.d24.1t01

\title{
Matizes da resistência: o cinema e as ditaduras da América do Sul
}

\author{
Fernando Seliprandy*
}

Abreu, Nuno Cesar; Suppia, Alfredo \& Freire, Marcius (org.) (2018). Golpe de vista: cinema e ditadura militar na América do Sul. São Paulo: Alameda. ISBN: 9788579394546.

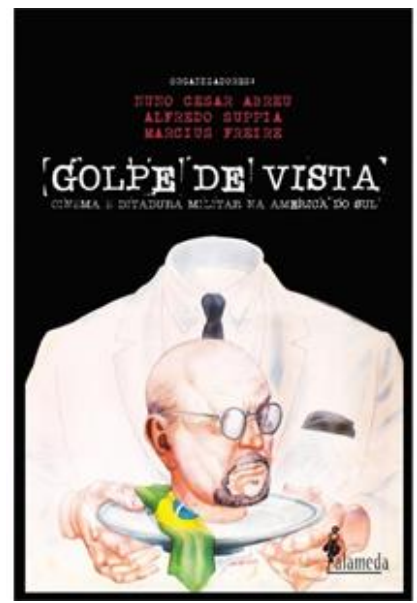

Os estudos dedicados aos cruzamentos entre audiovisual e ditaduras têm hoje uma pujança inequívoca. O livro Golpe de vista: cinema e ditadura militar na América do Sul, organizado por Nuno Cesar Abreu (in memoriam), Alfredo Suppia e Marcius Freire, é uma amostra patente disso. O quadro se amplia quando se pensa que, somente em 2018, surgem no Brasil outras duas coletâneas com temática análoga, frutos dos trabalhos de distintos núcleos de pesquisadores (Dellamore et al., 2018; Morettin; Napolitano, 2018). Em um contexto de acirrada disputa pelas versões do passado recente da região, a vivacidade das indagações sobre o período ditatorial pela ótica do cinema é muito mais do que uma conquista acadêmica a ser celebrada por quem se dedica ao assunto. Há aí também a resposta a um imperativo social urgente.

* Universidade de São Paulo, Faculdade de Filosofia, Letras e Ciências Humanas, Programa de Pós-Graduação em História Social. 05508-000, São Paulo, Brasil. Email: seliprandy@hotmail.com 
Essa urgência está escancarada já desde as primeiras linhas de Golpe de vista. O texto de apresentação finca os pés do livro na atual conjuntura sulamericana de estremecimento dos alicerces democráticos, repetidamente golpeados no Brasil particularmente desde 2016. Ora, quando tantos querem não só reescrever, mas reviver um regime de exceção, posicionar-se é um dever que os organizadores assumem sem tergiversações. Em tempos de descarados negacionismos, o rigor acadêmico coloca-se a serviço da defesa vigorosa da democracia. Como objeto de estudo, o cinema termina sendo também um espaço de resistência.

De fato, o tópico da resistência ao arbítrio é um eixo que atravessa os vinte capítulos da coletânea, divididos em duas partes: "Dossiê I - arquivos abertos”, em que a escala de análise dos textos é mais ampla, percorrendo temáticas estruturantes desse campo de estudos (a crítica na imprensa; os circuitos alternativos de exibição; o cinema militante; o cinema de exílio; os manifestos dos cineastas; o papel das cinematecas; a produção alinhada aos regimes; a censura e seus impactos nas formas expressivas e nas circulações culturais; os atores sociais retirados da invisibilidade); e "Dossiê II - recortes", que traz análises fílmicas verticalizadas, mergulhos minuciosos na matéria audiovisual em busca de significados latentes, em um corpus que vai desde títulos realizados no calor dos eventos até outros mais recentes, nos quais é a elaboração retrospectiva da memória o que está em jogo. Vale mencionar que o livro traz textos em espanhol e português, favorecendo uma vocação transnacional sulamericana anunciada já desde o subtítulo.

Se a "resistência" é um eixo entre as análises, não se trata de um eixo monolítico. Muito pelo contrário. O capítulo de Margarida Maria Adamatti sobre os textos da imprensa alternativa (Opinião, Movimento e Crítica) acerca dos contatos dos cinemanovistas com o regime brasileiro mostra muito bem que esse terreno histórico é muito mais movediço do que supõe a dicotomia estanque entre cooptação e resistência. Prestando atenção às nuances dos gêneros jornalísticos, a autora identifica os estratagemas de cineastas e críticos para se equilibrarem nas entrelinhas e nos interditos que marcam entrevistas, artigos informativos e colunas de opinião. Emerge da análise um gradiente de resistências negociadas, um quadro ambíguo no qual o ato de se expressar pelo cinema dependia de um Estado que ao mesmo tempo fomentava e reprimia, financiava e censurava.

Passando para a esfera da exibição, o capítulo de Cecilia Lacruz se dedica a um caso específico uruguaio que, pelo próprio fato de ser funestamente circunscrito, ilumina facetas inusitadas das circulações culturais: as sessões organizadas pelos presos políticos na penitenciária de Libertad durante a ditadura. 
O levantamento da programação dessas sessões feito por Lacruz mostra uma presença substantiva dos chamados "filmes de arte", revelando a possibilidade de formação de uma cultura cinematográfica naquele contexto carcerário. Tais circulações revestiam-se ali de um sentido de resistência, a resistência possível contra o rigor do confinamento e a anulação da individualidade dos detentos: o contato com experimentos estéticos que oxigenavam aquela atmosfera enclausurada; a experiência do cinema vivida coletivamente. É claro que neste caso também não se abandona o terreno das ambiguidades. Afinal, aos olhos dos carcereiros do regime, essa atividade cultural também não deixava de ser uma válvula de escape para eventuais rebeliões.

Mariano Mestman, em seu capítulo, dá sequência ao debate sobre os circuitos alternativos de exibição, agora com foco nas táticas do cinema militante levadas adiante pelo grupo Cine Liberación, da Argentina. O autor promove um instigante cotejamento entre, de um lado, os manifestos públicos do movimento e, de outro, uma documentação interna, com registros detalhados das experiências de difusão clandestina de La hora de los hornos (1968), de Fernando Solanas e Octavio Getino, pela Argentina. A conclusão é que a prática das exibições promovidas pelas unidades móveis de Cine Liberación não só nutre a gênese e o desdobramento das formulações conceituais do grupo sobre o "filme-ato", como também as ultrapassa com suas vicissitudes. Os rastros iluminam o programa e vice-versa. Fica claro aí o valor do trabalho paciente com os arquivos, da atenção aos testemunhos involuntários que dão a ver como o dia a dia militante forja e extrapola uma agenda declarada.

O texto de Javier Campo resgata um corpus fílmico nem sempre levado em conta nessa área de estudos: os documentários realizados por exilados argentinos fora do país entre 1976 e 1984. Analisando essa produção, o autor descreve uma inflexão formal e temática que acompanha os novos ares estéticos e as revisões políticas realizadas pelos exilados nos anos de desterro: a passagem, enfim, de um cinema documental de linguagem mais assertiva, calcado em imagens de arquivo, para outro de formas abertas, tendo no centro a palavra testemunhal; um paulatino abandono da retórica belicista revolucionária em nome da denúncia das violações perpetradas pelo regime. No fundo, é a própria ideia de resistência que passava por uma transformação crucial na distância do exílio, deixando para trás a utopia massacrada e extraindo do próprio massacre a força para a luta por direitos humanos e pela democracia. Eis aí mais uma faceta da capacidade de adaptação no terreno da resistência.

A abordagem das formulações programáticas na órbita dos cinemas novos latino-americanos tem sequência no capítulo de autoria de Ignacio Del Valle Dávila. Neste caso, o autor agrega ao debate sobre o grupo Cine Li- 
beración um cotejamento com as proposições de Glauber Rocha, enfatizando a metamorfose das ideias em uma espiral de fluxos e maturações. Del Valle Dávila realiza uma espécie de filologia dos textos dos manifestos de ambas as correntes, mostrando que, se, por um lado, os ares comuns da liberação nacional podiam levar a proposições antagônicas (a politização da "política dos autores" e a reivindicação da plena autonomia estético-ideológica por parte de Glauber; a realização coletiva e clandestina a serviço de uma agenda militante professada por Cine Liberación); por outro, as revisões e reformulações dos manifestos aparavam arestas e abriam margem para a superação de diferenças programáticas em nome de uma "frente" cinematográfica terceiro-mundista. É pela leitura cuidadosa que se descortina uma trama maleável de ressignificações, contrastes e distensões, revelando que nem só de sectarismos se fez o debate da esquerda radical nos anos 1960 e 1970.

Fabián Núñez desloca o olhar para outro ator fundamental naquele contexto: as cinematecas latino-americanas. O pesquisador mantém no horizonte, porém, o viés complexo de interpretação da resistência, que nas cinematecas assumia modalidades variadas concernentes a seu papel institucional: difusão, produção, formação, salvaguarda, articulação internacional, publicações. Núñez discute os caminhos pelos quais, na América Latina, o entusiasmo cinéfilo se misturava com a militância extracinematográfica, transformando as cinematecas em verdadeiros polos de resistência cultural. E dá a ver um circuito pleno de tensões, que inclui divergências e rivalidades entre cinematecas acerca da tática mais efetiva de atuação; subterfúgios e negociações com os regimes para sobreviver ao estrangulamento repressivo. No limite, segundo o autor, em um continente historicamente relapso com seu patrimônio cinematográfico, já a própria tarefa de preservar filmes pode ser lida como um ato subversivo.

Mas nem só de resistência se fez essa história. O capítulo de Luiz Dufuur sobre o cinema alinhado ao regime uruguaio joga luz sobre o outro espectro dos anos autoritários: aquele que oscila entre responsabilidades, colaboracionismos, cumplicidades, acomodações e omissões. Dufuur analisa casos em que, de acordo com sua análise, os filmes são usados como vetores ideológicos da ditadura, moldando o passado da nação uruguaia em função do presente ditatorial. Aqui o que está em jogo não são as transferências culturais operantes no tabuleiro de ressignificações, mas os vínculos entre as narrativas fílmicas e a cultura autoritária promovida pelo regime. O texto leva a pensar nesse reverso da resistência, igualmente matizado por uma paleta de zonas cinzentas.

Na sequência, o capítulo de Mariana Villaça coloca o leitor diante da contraface do cinema uruguaio naquele contexto. A autora descreve um fértil 
campo cinematográfico em Montevidéu às vésperas do golpe, embora já estivesse em curso um recrudescimento das medidas restritivas por parte das autoridades. Mostras, festivais, cineclubes, cinematecas, periódicos alternativos, tudo isso compunha um circuito cultural de esquerda que difundia filmes de combate, abertamente revolucionários, alimentando uma efervescência cinéfila atrelada à crescente radicalização política. O golpe de 1973, conforme Villaça, asfixiou essa atmosfera, fazendo proliferar as produções oficiais de propaganda do regime. Aos cinéfilos de esquerda sobraram espaços restritos para uma resistência cultural possível, cifrada, no bojo da qual mesmo o "cinema de autor" (outrora taxado de burguês) passava a cumprir a função de brecha contestatória.

O Peru ou, mais especificamente, o cinema andino entra no mapa com o capítulo de Carlos Reyna. Por meio de uma lei de fomento ao cinema, o regime nacionalista de esquerda instaurado em 1968 naquele país buscava criar as condições para a formação de uma indústria cinematográfica local. A análise de Reyna capta as contradições desse projeto, plasmadas em filmes que, se, por um lado, alçavam o camponês andino a um papel protagonista, rompendo com o centralismo limenho que dominou a história do cinema peruano até o início dos anos 1960; por outro, justamente ao valorizar o camponês, essas representações, fortemente mediadas pela cultura letrada, colocavam em segundo plano a identidade indígena em nome de uma assimilação à comunidade nacional. A questão, segundo o autor, era ainda mais complexa por se tratar de um contexto em que as estruturas de posse da terra eram alteradas por uma reforma agrária promovida pelas autoridades.

Os capítulos sumarizados até este ponto são aqueles que integram a primeira parte do livro, composta por análises que oferecem uma perspectiva mais panorâmica das relações entre cinema e ditaduras. Mas esses textos, é preciso ressaltar, possuem uma coerência entre si que ultrapassa a questão da escala de análise. De fato, essa leitura em conjunto revela uma rede de vasos comunicantes metodológicos entre as reflexões de cada autor, notadamente: a) o esmiuçar do gradiente das formas de resistência contra as ditaduras, rompendo com uma visão monolítica da luta opositora e superando a dicotomia simplista entre resistência versus cooptação; b) a pesquisa com fontes primárias extrafílmicas, iluminando novas facetas das imagens por meio de indagações minuciosas da documentação, sem se contentar com a aplicação redutora de conceitos-coringas para resolver as análises fílmicas; c) o mapeamento das circulações e transferências culturais, lembrando que todo circuito tem suas tensões, que os fluxos são feitos de ricos intercâmbios, mas também esbarram em complicadas arestas. 
Os textos incluídos na segunda parte do livro não abandonam essas linhas metodológicas gerais. O que difere na sequência da coletânea é a inclinação aos recortes mais circunscritos em cada capítulo: o exame de obras de um realizador específico; o cotejamento entre alguns títulos a partir de uma problemática comum; a reflexão guiada por um único filme. Muitas das temáticas abordadas pelos autores da primeira parte continuarão no horizonte das indagações, com destaque, mais uma vez, para a questão da resistência. Mas agora o olhar microscópico possibilita uma passagem do comentário à análise fílmica densa, uma atenção mais detida às imagens, uma decupagem da matéria audiovisual empreendida com mais vagar.

De saída, Marcius Freire se debruça sobre os dois curtas-metragens dedicados ao Brasil da série de contrainformação On vous parle de..., realizada por Chris Marker junto ao coletivo Société pour le lancement des œuvres nouvelles (SLON). Trata-se de On vous parle du Brésil: tortures (1969) e On vous parle du Brésil: Carlos Marighella (1970). No primeiro, Freire identifica a potência desencadeada pelo enquadramento em grande plano das fisionomias das testemunhas (presos políticos brasileiros libertados em troca do embaixador estadunidense Charles Elbrick), colocando o espectador face a face com a dor do torturado que denuncia os abusos sofridos no calor dos eventos. No segundo curta, a análise destaca o aspecto de colagem assumido pelo filme, criando sentidos a partir da superposição de materiais audiovisuais heterogêneos. Eis aí uma amostra da obra de um ensaísta engajado, alguém que assume abertamente um compromisso com as causas de seu tempo sem abrir mão de revolucionar a própria linguagem cinematográfica.

Francisco Elinaldo Teixeira propõe um rico diálogo entre Matou a família e foi ao cinema (1969), de Julio Bressane, e A idade da Terra (1980), de Glauber Rocha. O autor descreve, no primeiro caso, uma "energia contracultural" devastadora que serve de motor à alegoria do jugo ditatorial. No segundo, uma aposta no "poder espiritual multirreligioso" como força pós-revolucionária eivada de ambiguidades em seu flerte com o militarismo. É pela laboriosa análise fílmica que se descortinam essas facetas menos óbvias do político no cinema.

O capítulo de Caroline Gomes Leme examina três produções recentes a partir da questão do entrelaçamento de temporalidades: Corpo (2008), de Rubens Rewald e Rossana Foglia; Hoje (2011), de Tata Amaral; e A memória que me contam (2012), de Lucia Murat. A análise de Leme decifra os signos precisos por meio dos quais esses filmes mantêm em aberto o passado no presente, recusando-se a encapsular o período autoritário em narrativas encerradas em um tempo distante. Segundo a autora, os fantasmas, os legados, os entulhos e as conivências daqueles anos ganham uma atualidade desconcertante nessas 
obras, despertando os contemporâneos de seu contentamento com a "normalidade" democrática.

José Inacio de Melo e Souza se concentra em Fome de amor (1968), de Nelson Pereira dos Santos. O capítulo resgata o filme do desinteresse por parte do campo de estudos, contrapondo-se à ideia de que seria um mero "desvio" na carreira de Nelson. A leitura proposta por Souza insere essa obra no debate de seu tempo, ao lado de outros títulos que também buscaram equacionar a condição política brasileira após o golpe de 1964. De fato, a análise fílmica densa empreendida pelo autor escava o teor político conferido pelo cineasta a uma trama que, na origem, era banalmente folhetinesca. Nesse sentido, destaca-se a tematização do foquismo então em voga, cuja crise já se anunciava com a morte de Che Guevara.

O recorte de Carolina Amaral de Aguiar é o cinema realizado em solidariedade ao Chile após o golpe de 1973 no âmbito latino-americano. A autora descreve um rico circuito transnacional no qual o olhar "de fora" para a brutal derrubada da Unidade Popular (UP) variava conforme a conjuntura política do país desde onde se filmava. Em produções de Cuba e Nicarágua, a recémderrotada via pacífica chilena ao socialismo era objeto de solidariedade, mas também não deixava de ser alvo de um balanço crítico que acusava suas insuficiências à luz da via armada guevarista, que ganhava novo alento com a vitória sandinista em 1979. Nos casos de México e Venezuela, a questão dizia respeito à postura diplomática assumida por seus respectivos governos, seja na forma da acolhida dos exilados, propiciando-lhes condições de produção fílmica, seja pela abertura de espaço para encontros de cineastas latino-americanos. Surge daí um quadro no qual a solidariedade internacional ao Chile ganha distintos prismas, incluindo a revisão dos "erros" das esquerdas transandinas.

Reinaldo Cardenuto propõe uma análise em torno da polissemia do "despencar" no filme A queda (1976), de Ruy Guerra e Nelson Xavier. A queda literal do personagem operário é lida como metáfora de uma mudança de patamar do papel do povo na história: não mais o agente heroico de uma revolução inexorável, mas o portador de sintomas das perversidades da opressão, derivando entre a luta e a reprodução da violência. Desmoronada a teleologia totalizante da revolução, restam os focos de resistência repletos de incoerências. De acordo com Cardenuto, a forma fílmica imperfeita, descontrolada, é o meio de expressão desse universo decaído, acompanhando na decomposição estética a queda dos personagens e o desabamento dos projetos utópicos.

Maria Leandra Bizello analisa Ação entre amigos (1998), de Beto Brant, identificando, também nesse caso, os entrelaçamentos entre presente e passado. Na leitura proposta por Bizello, o complicador nesse filme são as encru- 
zilhadas que se formam nessa sobreposição de temporalidades: entre trauma individual e memória coletiva, entre justiçamento político e vingança pessoal.

O texto de Marina Soler Jorge conduz as reflexões para o terreno da série televisiva, fenômeno que ganha novo fôlego nos dias atuais. Com foco em Magnífica 70 (2015), criada por Cláudio Torres, Soler Jorge desvenda os modos pelos quais a série retrata o sistema de produção precário da Boca do Lixo sem abrir mão dos padrões de "qualidade" da ficção serial contemporânea. Conforme a autora, segue-se aí certa tendência de revalorização da cultura dita trash, conferindo-lhe estatuto de arte legítima. Além disso, se outros capítulos da coletânea se dedicam a resgatar o teor político de filmes de verniz folhetinesco, agora a análise vai no sentido contrário, identificando os artifícios pelos quais a trama de Magnífica 70 opera um esvaziamento da dimensão política que marcava as relações entre a produção da Boca do Lixo e a censura.

A ficção científica também comparece entre as análises, no capítulo assinado por Alfredo Suppia e Roberto de Souza Causo. Os autores traçam uma cartografia dos nexos entre ficção científica e política no cinema brasileiro, em filmes que oscilam entre o drama sério e a paródia, percorrendo um arco temporal que vai desde o pré-golpe de 1964 até o recente Branco sai, preto fica (2015), de Adirley Queirós. Dos prenúncios às permanências autoritárias, as análises vão esquadrinhando as críticas à modernização coagida embutidas nos ícones da ultramodernidade mobilizados em um contexto subdesenvolvido e repressivo.

Priscyla Bettim dedica-se à obra de Andrea Tonacci, recuperando os sentidos contestatórios da violência gratuita, do nonsense e do escracho visíveis em Olho por olho (1966), Blá blá blá (1968) e Bang bang (1971), todos de Tonacci. Na sequência, Bettim compartilha com o leitor uma rica entrevista com o realizador, desdobrando as questões abordadas em sua análise.

O último capítulo da coletânea, de Denise Tavares, dá visibilidade à filmografia de países nem sempre lembrados quando o tema são as interfaces entre cinema e ditaduras: Equador e Paraguai. Do primeiro, Tavares analisa Con mi corazón en Yambo (2011), de Fernanda Restrepo; do segundo, Cuchillo de palo (2010), de Renate Costa. Ambos fazem parte de uma das tendências cinematográficas atuais mais salientes na revisão do passado recente no continente: os documentários realizados por uma nova geração de familiares de vítimas da violência de Estado, marcados pelas vicissitudes da busca subjetiva. A análise de Tavares desvenda as persistências subterrâneas que afloram dessas memórias familiares, rastreando nos laços afetivos as violências ainda entranhadas no tecido social. Com isso, o capítulo fecha o ciclo da pauta da "resistência" que atravessa o livro, retomando em tom menor a reivindicação anunciada já 
desde o texto de apresentação da coletânea: rever o período autoritário à luz de um presente de fragilidade democrática.

No conjunto, Golpe de vista oferece ao leitor uma amostragem expressiva dos trabalhos sobre cinema e ditaduras realizados atualmente na região, com textos de pesquisadores que têm se destacado nesse campo de estudos. Só isso já faria dele uma obra incontornável para quem se dedica ao tema. Entretanto, suas ressonâncias ultrapassam o microcosmo acadêmico. Elas transbordam na crítica urgente de um presente no qual os legados autoritários ganham vigor inédito. Essa crítica não tem a forma do libelo, mas da investigação paciente que, por um lado, serve de antídoto contra os negacionismos que tentam minar a memória das esquerdas, virando do avesso o significado dos atos de resistência para legitimar a brutalidade estatal; por outro, essa indagação supera a idealização (celebrativa e, como fica cada vez mais claro hoje, equivocada) que superdimensiona uma resistência em bloco da sociedade contra os impulsos autoritários. Com um olhar atento, os textos reunidos em Golpe de vista mantêm a resistência na ordem do dia, revolvendo um terreno movediço de possibilidades e contradições que foi e que ainda precisa ser percorrido.

\section{Referências bibliográficas}

Dellamore, C.; Amato, G. \& Batista, N. (org.) (2018). A ditadura na tela: o cinema documentário e as memórias do regime militar brasileiro. Belo Horizonte: Faculdade de Filosofia e Ciências Humanas.

Morettin, E. \& Napolitano, M. (org.) (2018). O cinema e as ditaduras militares: contextos, memórias e representações audiovisuais. São Paulo: Intermeios. 